\title{
Os novos manicômios a céu aberto: cidade, racismo e loucura
}

The new open sky asylums: city, racism, and madness

\author{
Elizete Maria Menegat* \\ Marco José de Oliveira Duarte** \\ Vanessa de Fátima Ferreira***
}

\begin{abstract}
Resumo - O objetivo deste trabalho é discutir a indissociável transversalidade de certos fatores que configuram o perfil do louco na atualidade. Nesse sentido, consideramos, primeiramente, a cidade e os processos de urbanização conduzidos pelo moderno sistema capitalista como quadro socioespacial no qual a miséria e a loucura em massa emergiram e se estruturaram como fenômenos permanentes. Nas periferias, tais como o Brasil, que foram colonizadas pelo sistema capitalista mundial com base na escravidão da força de trabalho africana, a loucura persistiu, em todas as épocas, como doença dos pobres e negros. Na atualidade, quando a taxa de urbanização brasileira aproxima-se de $90 \%$ e coincide com a crise estrutural do sistema, observamos que a loucura tem maior incidência nos negros, os quais se encontram majoritariamente concentrados nas densas periferias das cidades, com os piores indicadores de habitação, emprego, renda, escolaridade e submetidos a toda sorte de violência.
\end{abstract}

Palavras-chave: cidade; racismo; loucura; capitalismo; raça negra.

\begin{abstract}
The aim of this paper is to discuss the inseparable transversality of certain factors that shape the madperson's profile today. In this sense, we first consider the city and the urbanization processes led by the modern capitalist system as the socio-spatial framework in which misery and madness emerged en masse as permanent phenomena. In periphery countries, such as Brazil, which were colonized by the world capitalist system based on the slavery of the African workforce, madness persisted throughout the ages as a disease of the black and poor. At present, when
\end{abstract}

\footnotetext{
* Arquiteta. Pós Doutora em Sociologia pela Universidade de Princeton (EUA) e Doutora em Planejamento Urbano e Regional pelo IPPUR/UFRJ. Professora Adjunta do Curso de Graduação e do Programa de Pós-Graduação em Serviço Social da Faculdade de Serviço Social da Universidade Federal de Juiz de Fora (UFJF). E-mail: em menegat@gmail.com. ORCID: https://orcid.org/0000-0002-8932-2019.

** Assistente Social. Pós Doutor em Políticas Sociais pela UCSal e Doutor em Serviço Social pela UERJ. Professor Adjunto do Curso de Graduação e do Programa de Pós-Graduação em Serviço Social da Faculdade de Serviço Social da Universidade Federal de Juiz de Fora (UFJF) e do Programa de Pós-Graduação em Serviço Social da Faculdade de Serviço Social da Universidade do Estado do Rio de Janeiro (UERJ). E-mail: majodu@gmail.com. ORCID: https://orcid.org/0000-0002-6395-1941.

*** Assistente Social. Graduada em Serviço Social pela Faculdade de Serviço Social da Universidade Federal de Juiz de Fora (UFJF). E-mail: vanessafatimaferreira@gmail.com. ORCID: https://orcid.org/0000-0001-8800-6877.
} 
\} OS NOVOS MANICÔMIOS A CÉU ABERTOS - MENEGAT, E. M.; DUARTE, M. J. O; FERREIRA, V. F. \}

DOI: $10.12957 /$ REP.2020.47217

the Brazilian urbanization rate approaches $90 \%$ and coincides with the structural crisis of the system, we observe that blacks are mostly concentrated in the dense peripheries of cities, with the worst indicators of housing, employment, income, education, and mental health.

Keywords: city; racism; madness; capitalism; black ethnicity.

\section{Para uma introdução: cidade capitalista e subjetividade}

Friederich Engels, Georg Simmel, Robert Park, Lewis Munford, Jane Jacobs, Mike Davis. Cada um ao seu modo, e ao seu tempo, observou que a configuração urbana moderna é um moinho tendencialmente destrutivo das formas de coesão social. Em 1845, o jovem Engels (1985) afirmava que a conduta individualista das massas, fortemente visível nas áreas centrais de grandes cidades, como Londres, era sintoma de uma sociedade doentia que tinha como fundamento das relações sociais a "guerra de todos contra todos".

A cidade e a urbanização modernas foram criadas a partir da divisão social e territorial do trabalho exigidas pela lógica competitiva de produção do valor, intrínseca ao moderno sistema capitalista de produção de mercadorias. No texto A metrópole e a vida mental, escrito em 1903, Simmel (1973) denominou de ar blasé uma dada característica comportamental a que tendem os indivíduos que vivem nas grandes cidades. A atitude blasé é uma atitude apática, insensível ou indiferente, que os sujeitos acabam incorporando a partir do universo impessoal das relações de troca dominadas pela relação-dinheiro: "Esse estado de ânimo [blasé] é o fiel estado subjetivo da economia do dinheiro interiorizada", afirmava Simmel (1973, p. 6).

Como equivalente geral, o dinheiro brutalmente reduz as diferenças qualitativas, de tudo e de todos, a um quantum de valor. As qualidades particulares dos sujeitos tendem a ser totalmente desvalorizadas em nome de uma cultura externa, objetivada a partir das trocas mediadas pelo dinheiro. "O dinheiro com toda sua ausência de cor e indiferença, torna-se o denominador comum de todos os valores; arranca irreparavelmente a essência das coisas, sua individualidade e sua incomparabilidade" (SIMMEL, 1973, p. 6).

As grandes cidades são a principal sede da produção, da troca e da acumulação de valor monetário. Por isso constituem, também, "a localização genuína da atitude blasé". Conforme Simmel (1973, p. 8), o processo violento de imposição de um modo de vida urbano, impessoal, vai consumir o sujeito internamente, "estirando os [seus] nervos brutalmente em uma e outra direção". A adoção desse comportamento competitivo e individualista por extensos segmentos das massas urbanas pode ser interpretado como o ponto de culminância de um dado patamar de acomodação do sofrimento psíquico, que se impõe ao indivíduo para que ele possa seguir disputando sua sobrevivência na moderna cidade capitalista.

A sobrevivência na cidade capitalista exige a formatação de uma subjetividade individualista, competitiva, inteiramente subordinada aos obje- 


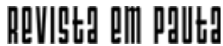

\} OS NOVOS MANICÔMIOS A CÉU ABERTOS - MENEGAT, E. M.; DUARTE, M. J. O; FERREIRA, V. F. \}

DOI: $10.12957 /$ REP.2020.47217

tivos autômatos do trabalho abstrato mediado por tecnologias cada vez mais agressivas. Uma tal subjetividade somente é alcançada depois de um contínuo e doloroso processo interno de rupturas e perdas, em grandes doses, daquela face da sensibilidade humana capaz de reconhecer, generosamente, o outro como semelhante.

Não se trata de discursar em favor de um retorno à aldeia e às formas comunitárias de reprodução da vida que existiram no passado - como, até certo ponto, fizeram os culturalistas da Escola de Chicago. Até porque essas formas socioespaciais foram constituídas pelas necessidades materiais e espirituais da humanidade em um tempo histórico singular e irreversível. Mas é forçoso reconhecer que a cidade capitalista, mais do que as suas ancestrais da Antiguidade greco-romana, produziu rupturas definitivas com um certo espírito de coletividade essencial à coesão humana. É certo que a forma violenta de reprodução da vida urbana moderna, com seu rol de exigências materiais e socioespaciais permanentemente modificadas, tem produzido quantidades de doentes mentais como em nenhuma época anterior.

\section{Sobre urbanização moderna e loucura em massa}

A estrutura socioespacial moderna é imanente ao moderno sistema mundial de produção de mercadorias. A moderna divisão territorial, entre centro e periferia, cidade e campo, foi "forjada a ferro, fogo e sangue" nos séculos XV, XVI e seguintes. Sua constituição é, portanto, indissociável da constituição do nascente sistema mundial de produção de mercadorias e da estrutura de um mundo centrado no trabalho abstrato que, então, emergia (MARX, 1982). Dada a sua compulsão interna para a expansão, esse sistema gradativa e violentamente precisa destruir, por onde passa, a forma e o conteúdo socioespacial diversificado das coletividades autônomas, tais como aldeias e comunidades.

As aldeias guardavam formas coletivas e orgânicas da reprodução material e espiritual da vida, como a produção de alimentos e outros bens, as redes de trocas diretas, os laços afetivos, as culturas subjetivas. Esses ingredientes garantiam o humus necessário para nutrir a coesão e o sentimento coletivo de pertencimento e de reconhecimento mútuo entre os indivíduos que compartilham os recursos de uma dada base territorial.

Não por acaso, entre meados do século XVII e do século XVIII, na Europa, a urbanização forçada de enormes contingentes de expropriados das terras de uso comunal coincidiu com os processos de enlouquecimento massivo examinados por Foucault (1978). Uma vez que foram violentamente separadas da propriedade dos meios de subsistência, essas massas, física e subjetivamente massacradas, mais cedo ou mais tarde, iniciaram sua marcha rumo à cidade. Aqui, viram-se diante das dificuldades de sobrevivência no universo urbano ultracompetitivo onde precisavam individualmente disputar 


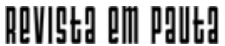

\} OS NOVOS MANICÔMIOS A CÉU ABERTOS - MENEGAT, E. M.; DUARTE, M. J. O; FERREIRA, V. F. \}

DOI: $10.12957 /$ REP.2020.47217

a venda da sua força de trabalho para adquirir, através de dinheiro, os meios de viver, incluindo a moradia (MARX, 1982).

Uma vez que o sistema capitalista não pode garantir a todos nem sequer o acesso ao mundo do trabalho explorado, numerosos excedentes foram transformados em hordas de miseráveis e de loucos. As práticas violentas de exclusão dos seus corpos, inutilizados pela sociedade do trabalho abstrato, através da tortura e do encarceramento em prisões, hospícios e asilos, estão descritas nos documentos de época analisados por Foucault (1978).

Na mesma época, no século XVIII, ainda dentro do período denominado de "acumulação primitiva" do moderno sistema mundial, o "banzo" era reconhecido, na África e na América, como a doença mental crônica que acometia, especialmente, grandes quantidades de africanos que, subjetivamente, não resistiam ao insuportável fardo de violências que começava com a destruição da aldeia, a desterritorialização e o translado intercontinental, culminando com os horrores da escravização (KANANOJA, 2018). Eram muitos os negros e negras que, acometidos pelo banzo, se suicidavam ou entravam em profundo e irreversível estado de depressão psicológica depois de espoliados, vendidos, estuprados, estropiados, escravizados e submetidos às durezas do trabalho, à fome e ao sistema de vigilância permanente em mocambos e senzalas. Os que recorriam ao suicídio utilizavam práticas de afogamento, autossufocação, envenenamento e armas brancas, ou deixavamse morrer pela inanição e tristeza (ODA, 2008). A crueldade dessa máquina de destruição física e subjetiva dos indígenas e dos negros escravizados instalou-se nas Américas com um único objetivo: produzir lucros para o sistemamundo capitalista que, então, surgia governado pelos exclusivos interesses de enriquecimento de uma elite branca, masculina e eurocêntrica.

A loucura, afirmou Foucault (1978, p. 163) em conhecida passagem, "não pode ser encontrada no estado selvagem. A loucura só existe em uma sociedade". Como fenômeno socialmente produzido, a loucura apresenta características próprias da civilização ou sociedade em cujo caldo fermentou. Muito embora a doença mental e seus sintomas tenha sido descrita na Antiguidade, é unicamente com a emergência da sociedade capitalista que ela se dissemina e se estrutura como epidemia entre as massas empobrecidas. A elevada frequência de distúrbios mentais, especialmente entre as massas urbanizadas, é, portanto, um fenômeno que emergiu na modernidade e se estruturou de modo crônico e permanente na sociedade capitalista.

Nesse sentido, há um fio condutor que liga tragédias de confinamento em massa e eliminação física dos portadores de transtornos mentais, tais como: 1) as "naus dos loucos", que eram embarcações lotadas de portadores de distúrbios mentais e abandonadas à deriva dos grandes rios que cortavam as principais cidades europeias, nos séculos XV e XVI; 2) a internação em massa dos loucos em prisões e asilos das grandes cidades europeias que se industrializavam e se modernizavam no século XVIII; 3) a elevada incidência do banzo entre a força de trabalho negra escravizada nas periferias 


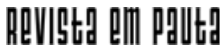

\} OS NOVOS MANICÔMIOS A CÉU ABERTOS - MENEGAT, E. M.; DUARTE, M. J. O; FERREIRA, V. F. \}

DOI: $10.12957 /$ REP.2020.47217

colonizadas pelo eurocentrismo, como o Brasil; 4) o encarceramento nos manicômios do século XIX e XX; 5) a concentração da população negra, pobre e louca nas favelas, periferias, guetos e campos de refugiados no século $\mathrm{XXI}$, pois seguem a mesma lógica de confinamento dos corpos que já não têm funcionalidade para o capital em crise aguda na atualidade (MENEGAT, 2019).

As raízes estruturais de tamanha catástrofe social devem ser buscadas na forma profundamente violenta como se constituiu e se estruturou espacial, racial e socialmente a civilização capitalista moderna. Dada a racionalidade perversa dessa engrenagem, em nenhum momento dos últimos 500 anos e em nenhum lugar do mundo a destruição psíquica de tão numerosos indivíduos foi considerada um problema realmente importante de saúde pública.

Miséria e loucura em massa são, pois, fenômenos crônicos e indissociáveis de um sistema que, depois de exercitar formas violentas de expropriação dos meios de vida de populações inteiras que viviam em comunidades autônomas, vai forçá-las a entrar nas cidades. Uma vez urbanizadas, as sucessivas gerações descendentes dessas massas obrigam-se a sobreviver ou como indivíduos assalariados, disciplinados pelo férreo regime de extração de mais-valia, ou - o que é ainda pior - como legiões de desocupados que compõem a numerosa fração dos excedentes da esfera do trabalho; esses, na ausência de alternativas, obrigam-se a viver das sobras, nos porões da sociedade, submetidos a todo tipo de violência e humilhação social. Esse último grupo concentra a maioria da população negra no Brasil. Desnecessário dizer que são os negros que enfrentam as maiores dificuldades para obter os meios de viver necessários à sua reprodução e de suas famílias no meio urbano. Dada essa condição limite posta para sua sobrevivência nas cidades atuais, somente por um golpe de sorte os negros podem escapar do risco de adoecimento físico e mental.

\section{Corpos negros como escravos e como "doentes mentais": a lógica manicomial e racista da ordem médica}

É no contexto da Pós-Abolição da escravatura inacabada, na afirmação da República, na transição do trabalho escravo para o trabalho livre, na emergência dos sobrantes expulsos das fazendas, nas políticas de embranquecimento, na disseminação das teorias científicas racistas no meio acadêmico e popular - da inferioridade do negro, da sua pouca inteligência, da propensão ao crime e da ideia de que o sangue negro estragava a raça branca, sendo a decadência da sociedade brasileira nessa nova era republicana - e na criminalização de práticas culturais e de socialização entre negros que emerge o Hospital Colônia de Barbacena (MG). 


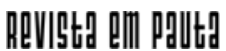

\} OS NOVOS MANICÔMIOS A CÉU ABERTOS - MENEGAT, E. M.; DUARTE, M. J. O; FERREIRA, V. F. \}

DOI: $10.12957 /$ REP.2020.47217

Arbex (2013), no seu livro Holocausto brasileiro', apresenta de forma contundente a realidade desumana desse maior manicômio do Brasil, inaugurado em 1903, conhecido como "Colônia". Com capacidade para 200 leitos, o hospital contava com uma média de 5.000 pacientes. Segundo a autora, da inauguração a 1980, o período de maior barbárie aconteceu entre 1930 e 1980, primeiro porque os critérios médicos desapareceram e, depois, em decorrência da Ditadura Civil-Militar, o caso foi blindado, contabilizando cerca de 60 mil pacientes mortos que por ali se internaram, quando pessoas eram internadas sem terem sintomas de loucura ou insanidade, mas eram isoladas pela ordem dos poderes familiares, médicos, jurídicos, policiais etc.

Desde o início do século XX, a falta de critério médico para as internações era rotina no lugar onde se padronizava tudo, inclusive os diagnósticos. Maria de Jesus, brasileira de apenas vinte e três anos, teve o Colônia como destino, em 1911, porque apresentava tristeza como sintoma. Assim como ela, a estimativa é que $70 \%$ dos atendidos não sofressem de doença mental. Apenas eram diferentes ou ameaçavam a ordem pública. Por isso, o Colônia tornou-se destino de desafetos, homossexuais, militantes políticos, mães solteiras, alcoolistas, mendigos, negros, pobres, pessoas sem documentos e todos os tipos de indesejados, inclusive os chamados insanos. A teoria eugenista, que sustentava a ideia de limpeza social, fortalecia o hospital e justificava seus abusos. Livrar a sociedade da escória, desfazendo-se dela, de preferência em local que a vista não pudesse alcançar. (ARBEX, 2013, p. 21 - grifos nossos).

Cabe ressaltar que o movimento eugênico brasileiro, oriundo da teoria da degenerescência de Morel (1857), teve início no século XX, apostando em medidas preventivas e sanitárias para o melhoramento da raça negra, como:

(a) higienização da população por meio do exame e do certificado prénupcial; (b) esterilização dos anormais. E não eram só negros e mestiços que ofereciam riscos para o futuro da nação, mas os 'anormais' e todos os pobres, que sempre foram responsáveis pela miséria moral e material e agora, pela degeneração da espécie. Em resumo, a grande preocupação dos médicos cientistas era com as elites, na reformulação da organização familiar (de origem colonial). O projeto científico evolucionista era assegurar uma prole sadia, evitando a reprodução das taras hereditárias que também degeneravam as raças. (LOBO, 2008, p. 203-204).

A autora ressalta que os sujeitos que foram mais violados eram negros, $80 \%$ de sua população interna, que eram usados no trabalho escravo

\footnotetext{
"Arbex não foi a única a comparar o "Colônia" ao holocausto nazista na Alemanha. Em 1979, o psiquiatra italiano antimanicomial Franco Basaglia visitou o hospício e disse, em uma coletiva de imprensa, "estive hoje num campo de concentração nazista. Em nenhum lugar do mundo presenciei uma tragédia como essa" (ARBEX, 2013, p. 13).
} 


\title{
ReVIStg am p pdutt
}

\} OS NOVOS MANICÔMIOS A CÉU ABERTOS - MENEGAT, E. M.; DUARTE, M. J. O; FERREIRA, V. F. \}

DOI: $10.12957 /$ REP.2020.47217

por ordem da gestão manicomial e parceria com a Prefeitura de Barbacena, para abrirem ruas, confeccionarem roupas (apesar de viverem nus), trabaIharem na horta etc. Arbex (2013) afirma que a única coisa que diferenciava das imagens feitas no "Colônia" dos campos de concentração nazista na Alemanha era exatamente o quesito raça/cor, a maioria era negra. No período compreendido entre 1930 e 1980, segundo a autora, foi que ocorreu o genocídio que atingiu majoritariamente a população negra e pobre. Ninguém foi punido por isso, nem gestores, funcionários, familiares e nem, principalmente, o Estado.

É necessário ressaltar que o período acima corresponde ao póscrise de 1929 e à crise do declínio da cafeicultura em solo brasileiro. No "Colônia" tudo dava lucro e, para sobreviver, a jornalista afirma que 1.853 corpos foram vendidos, maioria negros, entre 1969 e 1980, para faculdades de medicina do Brasil. O preço médio de um corpo, comumente denominado de "peça", era de 50 cruzeiros, o que equivale, nos dias de hoje, a aproximadamente $R \$ 600$ mil reais. A referência a peças é a mesma utilizada com os negros escravizados quando chegavam aos portos brasileiros pelos navios negreiros, vindos do Continente Africano, para serem comercializados como mercadorias aos senhores-patriarcais-brancos dos engenhos em terra Brasil.

A referida instituição continua aberta até hoje, tendo reformulado seu modelo assistencial manicomial para os poucos pacientes existentes e sendo mantida atualmente pela Fundação Hospitalar do estado de Minas Gerais (Fhemig). Existem cerca de 160 sobreviventes do Hospital Colônia, dos quais muitos continuam internados. São pessoas que ainda estão institucionalizadas, apesar de a maioria viver em Barbacena, nos serviços residenciais terapêuticos $(\mathrm{SRT})^{2}$, com muitas sequelas do período anterior da internação, por causa da alimentação precária e da desnutrição por longo período.

\section{Marcas do racismo como determinante social do sofrimento mental}

\author{
"De mim para mim, tenho certeza que não sou louco; \\ mas devido ao álcool, misturado com toda espécie de apreensões \\ que as dificuldades de minha vida material há seis anos me assoberbam, \\ de quando em quando dou sinais de loucura: delírio". (Lima Barreto).
}

Um caso emblemático, para começar esse texto, sobre racismo e sofrimento mental, agravado pelas desigualdades sociais e territoriais, como nos afirma Lima Barreto (1993, p. 23) sobre as dificuldades da vida material, centra-se na pessoa de Joselita Souza. Essa mulher negra, pobre e mãe, mo-

\footnotetext{
${ }^{2}$ O Serviço Residencial Terapêutico (SRT) - residência terapêutica ou, simplesmente, "moradia" - são casas localizadas no espaço urbano, constituídas para responder às necessidades de moradia de pessoas portadoras de transtornos mentais graves, institucionalizadas há anos em hospitais psiquiátricos que não contam com suporte familiar e social.
} 


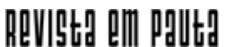

\} OS NOVOS MANICÔMIOS A CÉU ABERTOS - MENEGAT, E. M.; DUARTE, M. J. O; FERREIRA, V. F. \}

DOI: $10.12957 /$ REP.2020.47217

radora do Morro da Lagartixa, no Complexo da Pedreira, em Costa Barros, bairro da Zona Norte da cidade do Rio de Janeiro, veio a óbito vítima de parada cardiorrespiratória, em consequência de anemia e pneumonia, mas, principalmente, pela depressão, após sete meses e 13 dias da perda do seu filho Roberto Silva de Souza (16), que foi assassinado junto com Carlos Eduardo (16), Cleiton (18), Wilton (20) e Wesley (25). Eles estavam dentro do carro, um Palio branco, que foi metralhado com 111 tiros disparados ${ }^{3}$ por quatro policiais do $41^{\circ}$ Batalhão da Polícia Militar do estado do Rio de Janeiro (PMERJ), de Irajá.

Na noite do crime, dia 28 de novembro de 2015, sábado, os cinco jovens voltavam do Parque Madureira, onde foram comemorar o primeiro salário de Roberto, como Jovem Aprendiz, que há um mês trabalhava num supermercado e custeava o seu curso de Auxiliar de Administração. Algumas pessoas, segundo as reportagens de jornais e meios de comunicação em geral da época, ainda ouviram os gritos dos jovens dizendo "Não atira, somos moradores!", mas não somente isso, também trabalhavam e estudavam.

Jorge Roberto, pai de Roberto, foi um dos primeiros a chegar e sofrer ao ver seu filho dentro do carro. Os outros familiares foram chegando também e registrando a imagem que ficaria impregnada para sempre em suas mentes, e, em alguns casos, com graves repercussões de sofrimento mental, como a depressão, que ocorreu com Joselita, mas também com Mônica, mãe de Cleiton, e com Márcia, mãe de Wilton. Essa última ainda foi ameaçada pelos policiais por ter visto "plantarem" uma arma próxima ao carro, em cima de um dos pneus, tirando a chave do contato e jogando no porta-malas do veículo.

Casos como esse são mais frequentes do que as notícias se propõem a divulgar. A depressão definha o corpo e a mente; contudo, em situação de violência, com fator de estresse muito potente e com as marcas sociais da pobreza, esse quadro é ainda mais agravado, o que em muito determina socialmente os transtornos mentais causados, indelevelmente, pelo sofrimento social. Nisso o racismo se inclui como determinante estruturante e marcador social de diferença nas relações sociais. Particularmente, o racismo estrutural (ALMEIDA, 2018) demonstra, historicamente, a questão racial como constitutiva das desigualdades sociais na formação social brasileira pelo Estado capitalista e sua necropolítica (MBEMBE, 2011).

Revela-se, assim, a sobrevivência da matriz colonial no contexto contemporâneo do Brasil, sustentando uma dimensão racializada, na medida em que impõe a condição subalterna à população negra. Uma crítica da razão negra (MBEMBE, 2013), portanto, se faz necessária, pois o neoliberalismo, como face atual e devastadora do capitalismo, produz desempregados, indivíduos descartáveis, favelados, refugiados, imigrantes e toda uma horda de seres matáveis, expostos à morte e não passíveis de luto (BUTLER, 2015).

${ }^{3}$ Cabe ressaltar que esse foi o mesmo número dos oficialmente mortos no Massacre do Carandiru. 


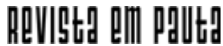

\} OS NOVOS MANICÔMIOS A CÉU ABERTOS - MENEGAT, E. M.; DUARTE, M. J. O; FERREIRA, V. F. \}

DOI: $10.12957 /$ REP.2020.47217

Na gestão da vida, inventam-se e reinventam-se hierarquias, classificações, assimetrias, discriminações, em que a religião, os valores morais e culturais vêm substituir o lugar da biologia como fundamento da discriminação, ao mesmo tempo em que se sobrepõem a ela. Assim, analisar as marcas do racismo como determinante social do sofrimento mental é colocar, na cena do debate, as questões que se relacionam, se interseccionam e se articulam, principalmente porque o que está sendo demandado pela população negra é a proteção e a atenção às vidas por parte do Estado. O mesmo Estado que, contraditoriamente, de forma aparente, sustenta um discurso oficial de proteção social a esses sujeitos, na medida em que se tem um leque de normativas legais e jurídicas em diversos âmbitos setoriais. Ou seja, no seu sentido formal, apesar das conquistas protagonizadas pelo movimento negro nos últimos anos, essas medidas legais se mostram frágeis, precárias e, particularmente, ameaçadas na sustentação política e econômica de suas políticas públicas voltadas para essa população.

Dessa maneira, ao tomar o tema da saúde mental e do racismo, pretende-se tratar de dados concretos dessa realidade, a partir de uma análise histórica e crítica, de como essa população e sua demanda social vêm sendo respondidas pelo Estado no seu "fazer viver, deixar morrer" (FOUCAULT, 1999), revelando que o que está em jogo é o tema do poder em seus mecanismos de intervenção e de constituição de dispositivos e estratégias. Portanto, trata-se de perguntar, em seus mecanismos, seus efeitos e suas relações, pelos dispositivos de poder que são exercidos nos diferentes domínios da sociedade, mas, em particular, para nossa análise, sobre a não responsabilização do Estado em efetivar de forma concreta a defesa, a cidadania e os direitos da população negra.

Butler (2015), em sua obra Quadros de guerra, mais especificamente no tópico Vida precária, vida passível de luto, afirma que nem tudo que está vivo é uma vida, e discorre sobre a precariedade do que chamamos vida e seus enquadramentos. Diz ela:

A precariedade implica viver socialmente, isto é, o fato de que a vida de alguém está sempre, de alguma forma, nas mãos do outro. Isto implica estarmos expostos não somente àqueles que conhecemos, mas também àqueles que não conhecemos, isto é, dependemos das pessoas que conhecemos, das que conhecemos superficialmente e das que desconhecemos totalmente. (BUTLER, 2015, p. 43).

Portanto, para a autora, há vidas reconhecidas como tais, as vidas que importam, as que são passíveis de luto. São, tecnicamente, para os segmentos sociais que habitam os condomínios de luxo, as pessoas brancas, que estão nos espaços de poder, onde se vê o espetáculo ou das janelas ou da TV, isento dos efeitos das movimentações das forças policiais que matam vidas precárias. Essas, porém, não importam, não serão choradas, são menos vida, ainda que estejam contidas em um ser vivo. É uma questão de enqua- 


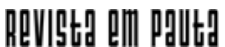

\} OS NOVOS MANICÔMIOS A CÉU ABERTOS - MENEGAT, E. M.; DUARTE, M. J. O; FERREIRA, V. F. \}

DOI: $10.12957 /$ REP.2020.47217

dramento, e é isso que afirma Butler (2015). Se alguém morrer esta noite no Complexo da Pedreira, ou no da Maré, ou no do Alemão, ninguém no Leblon ou em Ipanema vai chorar por isso, porque, se não for bandido, poderia até vir a ser, mas bandido bom, todo mundo sabe, é bandido morto.

O mesmo velho jogo de sempre. Quem decide quem pode morrer? Quem determina quais vidas importam? Quem usa fuzil para matar com autorização? Quem usa fuzil para matar sem autorização? Porque é disso que se trata afinal. O senhor da guerra não gosta de gente. Ou melhor: só gosta de algumas!

Assim, como interroga Spivak (2010), numa perspectiva pós-colonial, "pode o subalterno falar?". Desenha-se, nessa indagação, a crítica ao lugar da subalternidade e as diversas hierarquias, de raça, de gênero, de sexualidade e de classe, hegemonizadas pela política capitalística, neoliberal e marcada pelo regime de exceção, que territorializa os sujeitos, enquadrando, rotulando, estigmatizando e etiquetando seus corpos.

Aqui, pretende-se imprimir uma outra narrativa, a partir dos corpospolíticos-negros, numa tessitura de poder-resistência, afirmando que os corpos negros nas ruas, nas favelas, nas periferias, nos hospícios, nas prisões, importam, não serão ditos mais como anormais, abjetos, doentes, matáveis, alijados, sem luto e em pecados. Propõe-se afirmar os corpos-vivos, corpos em luta, a partir de outros regimes de verdade, de resistências.

\section{Notas sobre a definição do perfil do louco nas grandes cidades brasileiras}

Sobre as correlações entre gênero, renda e loucura:

Ludermir (2008) realizou uma ampla revisão bibliográfica, que incluiu reconhecidos autores nacionais e internacionais, com o objetivo de sintetizar os resultados de pesquisas sobre "as relações entre desigualdades de classe e gênero e saúde mental nas cidades". Conforme a autora, o conjunto das pesquisas que ela examinou convergiu no seguinte achado: "alta prevalência dos transtornos mentais comuns em mulheres, nos excluídos do mercado formal de trabalho, nos indivíduos de baixa renda e nos de baixa escolaridade" que atualmente vivem nas cidades ${ }^{4}$ (LUDERMIR, 2008, p. 451).

No que diz respeito ao gênero, alguns pesquisadores chegaram a afirmar que as mulheres têm uma prevalência de ansiedade e depressão duas a três vezes maior do que os homens. Apesar de constatar que os autores dos artigos que ela analisou não utilizavam conceitos e parâmetros comuns

\footnotetext{
${ }^{4} \mathrm{O}$ termo transtornos mentais comuns (TMC) foi criado em 1992 por Goldberg e Huxly, para designar um conjunto de sintomas não psicóticos que habitualmente estão relacionados com quadros subclínicos de ansiedade, depressão e estresse, os quais, pela sua elevada prevalência nos centros de atenção primária à saúde, são considerados como um dos maiores problemas de saúde pública mundial (MURCHO et al., 2016).
} 


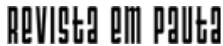

\} OS NOVOS MANICÔMIOS A CÉU ABERTOS - MENEGAT, E. M.; DUARTE, M. J. O; FERREIRA, V. F. \}

DOI: $10.12957 /$ REP.2020.47217

para definir "pobreza", "desigualdades sociais" e "baixa renda", Ludermir (2008) considerou que, ainda assim, os achados das pesquisas na área da epidemiologia psiquiátrica são persistentes e muito consistentes. Ela destaca, ainda, que os pesquisadores que incluíram a variável emprego/desemprego encontraram, persistentemente, prevalência de transtornos mentais entre os desempregados e desocupados pertencentes a grupos familiares de baixa renda, quando comparados com os que estão trabalhando (LUDERMIR, 2008).

Gonçalves et al. (2014) apresentaram os resultados de uma pesquisa primária realizada no Brasil, que investigou as taxas de transtornos mentais comuns e suas relações com características sociodemográficas em quatro capitais: Rio de Janeiro, São Paulo, Fortaleza e Porto Alegre. Foram coletados dados de 1.857 usuários de equipamentos de atenção primária à saúde nessas capitais. Os pesquisadores encontraram os seguintes dados sobre a taxa de transtornos mentais comuns entre os usuários de equipamentos de atenção primária à saúde: 51,9\% (Rio de Janeiro); 53,3\% (São Paulo); $64,3 \%$ (Fortaleza) e $57,7 \%$ (Porto Alegre). Sobre a prevalência dos transtornos mentais comuns, os autores afirmam: "Problemas de saúde mental foram especialmente altos em mulheres, desempregados, em pessoas com baixa escolaridade e baixa renda" (GONÇALVES et al., 2014, p. 625).

Os pacientes com transtornos mentais atendidos nos centros de saúde das quatro capitais pesquisadas pelo grupo eram, em sua grande maioria, não brancos $(70,8 \%)$, mulheres $(77,3 \%)$, com idade acima de 35 anos, com mais de quatro anos de estudo, casadas ou vivendo com companheiro. A maioria das mulheres autodeclarou-se não branca (non-white). Um elevado percentual dos pacientes $(90,8 \%)$ declarou renda média familiar inferior a dois salários mínimos (450 US\$). Cerca de $1 / 3$ dos pacientes declarou renda familiar abaixo de meio salário mínimo (GONÇALVES et al., 2014). Sobre os transtornos mentais comuns, os pesquisadores observaram maior incidência da depressão e da ansiedade no conjunto dos pacientes nas quatro capitais.

É interessante observar que os autores desse estudo incluíram o quesito raça/cor - através das categorias branco/não branco - na coleta de dados. Apesar de registrarem que $70,8 \%$ do universo autodeclarou-se não branco, os autores não inscreveram esse achado em suas análises. Por outro lado, observamos com especial atenção que Gonçalves et al. (2014) destacaram, no interior da categoria genérica "baixa renda", um setor com ainda maior prevalência de transtornos mentais: a categoria "desempregados". Eles enfatizam que em torno de $30 \%$ dos portadores de transtornos declararam renda familiar inferior a 1/2 salário mínimo.

Para tecermos uma ideia das dimensões do problema do desemprego e desocupação nas quatro capitais, as taxas de ocupação (total de ocupados no mercado formal, informal e precário) eram, em 2015: São Paulo, 48,9\%; Rio de Janeiro, 43,1\%; Fortaleza, 34,0\%, Porto Alegre, 57,4\%. Obser- 


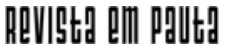

\} OS NOVOS MANICÔMIOS A CÉU ABERTOS - MENEGAT, E. M.; DUARTE, M. J. O; FERREIRA, V. F. \}

DOI: $10.12957 /$ REP.2020.47217

va-se que Fortaleza, uma cidade com 2.627.482 habitantes, tem apenas $34 \%$ do total da população economicamente ativa ocupada em atividades econômicas. Porto Alegre é, entre as quatro, a única capital que tem um percentual superior a $50 \%$ da PEA ocupada. Nas demais capitais, o desemprego e a desocupação atingem mais da metade da população em idade de trabalhar (IBGE, 2015).

De maneira semelhante, Ludermir (2008) referiu-se aos "excluídos do mercado formal de trabalho", grupo que pode incluir tanto os precarizados, como os desempregados e desocupados, cujo número cresce desmedidamente no atual período de crise. Chamamos a atenção sobre a relevância dessa informação, certamente indispensável para compreender as especificidades dos desafios que precisam ser enfrentados pelos indivíduos que não dispõem de dinheiro para acessar os meios de viver, num mundo urbanizado onde absolutamente tudo é mercantilizado.

Sobre correlações entre raça/cor, periferia urbana e loucura:

Zanello e Silva (2012) analisaram os sintomas e os diagnósticos de 237 prontuários de portadores de transtornos mentais que foram internados em dois hospitais grandes, em Brasília. No total, 27,5\% dos prontuários analisados eram de homens e $59,6 \%$ de mulheres. Destas, $14,4 \%$ eram trabaIhadoras domésticas e 33\% ocupadas com as atividades do lar. O percentual de pacientes internados que moravam em Ceilândia, Taguatinga e Samambaia, ou seja, a periferia pobre e miserável de Brasília, alcançou 60,7\%.

Conforme os autores, o perfil biométrico levantado apontou "para mulheres negras, pobres e domésticas" (ZANELLO; SILVA, 2012, p. 275). Os autores teceram profunda crítica à forma como foram registradas as informações sobre os pacientes nos prontuários examinados. Observaram que havia um grande silêncio sobre determinadas características associadas às condições materiais e existenciais que favorecem o sofrimento mental. Por exemplo, queixam-se de não terem encontrado dados importantes sobre renda, habitação e demais condições de vida. Apenas cerca de $30 \%$ dos prontuários traziam informações sobre raça/cor. Destes, $62,70 \%$ foram registrados como pretos e pardos.

Sabe-se que a maioria dos portadores de TMC não recebe tratamento. Além disso, os que chegam a alcançar atendimento de profissionais da saúde, em geral, são submetidos a medicamentos que produzem dependência química lícita. Zanello e Silva (2012, p. 277) encontraram dados sobre o uso intenso de diazepan pelas mulheres, o que vem confirmar pesquisas que fazem referências ao uso indiscriminado de benzodiazepínicos neste estrato da população. A ação desse tipo de medicação é, apenas, suspender, artificialmente, os sintomas do sofrimento no sujeito. Nesse sentido, é meramente uma "medicalização de problemas sociais".

Smolen e Araújo (2017) realizaram uma revisão sistemática da literatura nacional e internacional sobre doença mental e raça/cor no Brasil. Ao todo, analisaram 14 artigos. Eles salientam que há pouca pesquisa sobre 


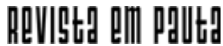

\} OS NOVOS MANICÔMIOS A CÉU ABERTOS - MENEGAT, E. M.; DUARTE, M. J. O; FERREIRA, V. F. \}

DOI: $10.12957 /$ REP.2020.47217

o tema, pois, em geral, os pesquisadores da área da saúde mental não incluem o quesito raça/cor nos instrumentos de coleta de dados.

Apesar das dificuldades encontradas, ainda assim os autores afirmam que "os estudos transversais que existem sobre transtornos mentais e raça identificados nessa revisão sugerem que a prevalência de transtornos mentais é maior na população negra do que na população branca (SMOLEN; ARAÚJO, 2017, p. 4026). Esses autores observaram a dificuldade de comparar dados de pesquisas que fizeram uso de conceitos e categorias muito diversas para expressar a cor da pele. Assim, em vez das cinco categorias empregadas pelo IBGE - branco, preto, pardo, amarelo e indígena - os artigos analisados utilizaram um arco-íris de categorias, como mulato, moreno, não branco, preto, negro etc. Conforme os autores, alguns estudos chegaram a registrar as características de raça/cor dos indivíduos pesquisados, contabilizaram os resultados, mas não produziram análises.

Podemos afirmar que há evidências empíricas, amplamente compartilhadas pelos pesquisadores e profissionais da área da saúde, de que as doenças mentais têm maior incidência entre os negros do que entre os brancos. Contudo, há, ainda, pouca pesquisa estatística que confirme esse fato. Por isso, são igualmente poucas as pesquisas que ousam analisar correlações entre raça/cor e a prevalência de transtornos mentais no Brasil.

Acreditamos que a omissão de características essenciais na percepção do perfil do portador de transtornos mentais favorece o encobrimento das origens profundas do seu sofrimento. Um movimento nesse sentido deve relacionar as doenças mentais com o racismo e a longa história de violências sofrida pela população negra, especialmente pelas mulheres negras, que vivem concentradas nas periferias das cidades brasileiras (FERREIRA, 2018).

\section{Considerações finais}

Miséria e loucura em massa são fenômenos crônicos e indissociáveis de um sistema que, depois de exercitar formas violentas de expropriação dos meios de vida de populações inteiras que viviam em comunidades autônomas, irá forçá-las a entrar nas cidades. Uma vez urbanizadas, as sucessivas gerações descendentes dessas massas obrigam-se a sobreviver ou como indivíduos assalariados, disciplinados pelo férreo regime de extração de maisvalia, ou - o que é ainda pior - como legiões de desocupados que compõem a numerosa fração dos excedentes da esfera do trabalho que, na ausência de alternativas, obrigam-se a viver das sobras, nos porões da sociedade, submetidos a todo tipo de violência e humilhação social.

Esse último grupo concentra a maioria da população negra no Brasil. Desnecessário dizer que são os negros que enfrentam as maiores dificuldades para obter os meios de viver necessários à sua reprodução e de suas famílias no meio urbano. Dada essa condição limite posta para sua 


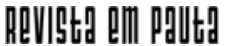

\} OS NOVOS MANICÔMIOS A CÉU ABERTOS - MENEGAT, E. M.; DUARTE, M. J. O; FERREIRA, V. F. \}

DOI: $10.12957 /$ REP.2020.47217

sobrevivência nas cidades atuais, somente por um golpe de sorte os negros podem escapar do risco de adoecimento mental e de outras tragédias sociais:

Tragédias como a do Colônia nos colocam frente a frente com a intolerância social que continua a produzir massacres: Carandiru, Candelária, Vigário Geral, Favela da Chatuba são apenas novos nomes para velhas formas de extermínio. Ontem foram os judeus e os loucos, hoje os indesejáveis são os pobres, os negros, os dependentes químicos, e, com eles, temos o retorno das internações compulsórias temporárias. Será a reedição dos abusos sob a forma de política de saúde pública? (ARBEX, 2013, p. 209).

Em um contexto em que as políticas públicas foram propositalmente excludentes para a população negra, foram graves as consequências para sua situação econômica e sua saúde mental. As novas tecnologias de controle social fabricadas pelo racismo brasileiro exacerbado pelo neoconservadorismo de fundo moral, higienista, medicalizante, punitivista e fascista, vêm se mostrando em sua forma mais radical de exclusão e morte.

Assim, a democracia só é viável se a intolerância for reconhecida, enfrentada, combatida e interpelada radicalmente, de forma coletiva, inclusive com a produção de saberes locais e específicos de resistências, pelos segmentos sociais que sofrem a violência do racismo, do sexismo e da LGBTQIfobia. 


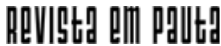

\} OS NOVOS MANICÔMIOS A CÉU ABERTOS - MENEGAT, E. M.; DUARTE, M. J. O; FERREIRA, V. F. \}

DOI: $10.12957 /$ REP.2020.47217

\section{Referências}

ALMEIDA, S. L. de. O que é racismo estrutural? Belo Horizonte: Letramento, 2018.

ARBEX, D. Holocausto brasileiro: vida, genocídio e 60 mil mortes no maior hospício do Brasil. São Paulo: Geração Editorial, 2013.

BRASIL. Ministério da Saúde. Residências terapêuticas: o que são, para que servem. Brasília: Ministério da Saúde, 2004.

BUTLER, J. Quadros de guerra: quando a vida é passível de luto? Rio de Janeiro: Civilização Brasileira, 2015.

ENGELS, F. A situação da classe trabalhadora na Inglaterra. São Paulo: Global, 1985.

FERREIRA, V. de F. G. Cor e dor: um estudo sobre racismo e sofrimento psíquico. Trabalho de Conclusão de Curso (Bacharelado em Serviço Social) Universidade Federal de Juiz de Fora, Juiz de Fora, 2018.

FOUCAULT, M. História da loucura na idade clássica. São Paulo: Perspectiva, 1978.

FOUCAULT, M. Em defesa da sociedade. São Paulo: Martins Fontes, 1999.

GOÇALVES, D. A. et al. Brazilian multicenter study of commom mental disorders in primary care: rates and related social and demographic factors. Cadernos de Saúde Pública, Rio de Janeiro, v. 30, n. 3, mar. 2014.

IBGE. Cidades-2015. 2015. Disponível em: https://cidades.ibge.gov.br. Acesso em: 12 mar. 2017.

KANANOJA, K. As raízes africanas de uma doença brasileira: o banzo em Angola nos séculos XVII e XVIII. Ponta de Lança, São Cristóvão, v. 12, n. 23, jul./dez. 2018.

KURZ, R. Seres humanos não rentáveis: ensaio sobre a relação entre história da modernização, crise e darwinismo social neoliberal. Ano. Disponível em: http://www.obeco-online.org/rkurz254.htm. Acesso em: 12 dez. 2015.

LOBO, L. F. Os infames da história: pobres, escravos e deficientes no Brasil. Rio de Janeiro: Lamparina, 2008.

LUDERMIR, A. B. Desigualdades de classe e gênero e saúde mental nas cidades. Phisys, Rio de Janeiro, v. 18, n. 3, set. 2008. Disponível em: http:/ /www.scielo.br/scielo.php?pid=S0103-73312008000300005\&script=sci abstract\&tlng=pt. Acesso em: 12 abr. 2019.

MARX, K. O capital: crítica da economia política. Tomo I. São Paulo: Abril Cultural, 1982.

MBEMBE, A. Necropolítica. São Paulo: N-1, 2011. 


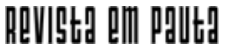

\} OS NOVOS MANICÔMIOS A CÉU ABERTOS - MENEGAT, E. M.; DUARTE, M. J. O; FERREIRA, V. F. \}

DOI: $10.12957 /$ REP.2020.47217

MBEMBE, A. A razão negra. São Paulo: N-1, 2013.

MENEGAT, M. A crítica do capitalismo em tempo de catástrofe. Rio de Janeiro: Consequência, 2019.

MOREL, B.-A. Traité des dégénérescences physiques, intelectuelles et morales de l'espèce humaine et les causes qui produisent ces variétés maladives. Paris: Baillière, 1857.

MURCHO, N. et al. Transtornos mentais comuns nos cuidados de saúde primários: um estudo de revisão. Revista portuguesa de enfermagem de saúde mental, n. 15, jun. 2016.

ODA, A. M. G. R. Escravidão e nostalgia no Brasil: o banzo. Revista Latinoamericana de Psicopatologia Fundamental, São Paulo, v. 11, n. 4, dez. 2008.

SERPA JR, O. D. de. O degenerado. Revista História, Ciências, Saúde - Manguinhos, Rio de Janeiro, v. 17, n. 2, dez., 2010. Disponível em: http://www. scielo.br/pdf/hcsm/v17s2/11.pdf. Acesso em: 20 nov. 2019.

SILVA, D. F. da; SANTANA, P. R. de. Transtornos mentais e pobreza no Brasil: uma revisão sistemátia. Revista Tempus Actas de Saúde Coletiva, Brasília, v. 6, n. 4, 2012. Disponível em: http://www.tempusactas.unb.br/index.php/ tempus/article/view/1214/1099. Acesso em: 12 abr. 2019.

SIMMEL, G. A metrópole e a vida menta. In: VELHO, O. G. (org.). O fenômeno urbano. Rio de Janeiro: Zahar, 1973.

SMOLEN, J. R.; ARAÚJO, E. M. Raça/cor da pele e transtornos mentais no Brasil: uma revisão sistemática. Ciência e Saúde Coletiva, v. 22, n. 12, 2017. Disponível em: http://www.scielo.br/scielo.php?script=sci_abstract \&pid=S1413-81232017021204021\&lng=pt\&nrm=iso. Acesso em: 25 mar. 2019.

SPIVAK, G. C. Pode o subalterno falar? Belo Horizonte: Ed. UFMG, 2010. ZANELLO, V.; SILVA, R. Saúde mental, gênero e violência estrutural. Revista Bioética, v. 20, n. 2, 2012. Disponível em:

http://revistabioetica.cfm.org.br/index.php/revista_bioetica/article/view/745. Acesso em: 25 mar. 2019.

DOI: $10.12957 /$ rep.2020.47217

Recebido em 21 de julho de 2019. Aprovado para publicação em 06 de outubro de 2019.

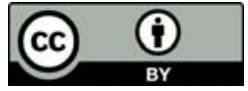

A Revista Em Pauta: Teoria Social e Realidade Contemporânea está licenciada com uma Licença Creative Commons Atribuição 4.0 Internacional. 